\title{
Comparison of Rate and Rhythm Control in Hypertension Patients With Atrial Fibrillation
}

\author{
Ahmet Yildiz, MD; Zerrin Yigit, MD*; Baris Okcun, MD*; Murat Baskurt, MD**; \\ Kadriye Ortak, MD**; Aysem Kaya, PhD*; Serdar Kucukoglu, MD*
}

\begin{abstract}
Background Atrial fibrillation (AF) is a very common cardiac arrhythmia, and is associated with an increased mortality in patients with hypertension. Whether the best therapeutic approach for these patients is to restore sinus rhythm (SR) or to adequately control the ventricular rate is still controversial. The aim of this study is to compare both strategies in patients with hypertension.

Methods and Results Two hundred and twenty-one patients with hypertension and AF of duration $>48 \mathrm{~h}$ were randomly assigned to either the rhythm $(n=155)$ or rate $(n=66)$ control group. Exercise capacity was improved in the rhythm control group in the $1^{\text {st }}$ year of the study $(\mathrm{p}<0.0001)$. There were no statistically significant differences in the embolic event rate and the total mortality between the 2 groups at the end of the study $(\mathrm{p}=\mathrm{NS})$.

Conclusions Although restoring and maintaining SR had a beneficial effect on exercise capacity in patients with hypertension and AF, no significant difference was found in terms of the total mortality and the embolic event rates. Thus, rate control is an acceptable primary strategy in patients with AF and hypertension. (Circ J 2008; 72: 705-708)
\end{abstract}

Key Words: Atrial fibrillation; Cardioversion; Hypertension

$A$ trial fibrillation $(\mathrm{AF})$ is the most frequent reason for hospital admission and is also the most common sustained cardiac arrhythmia, occurring in $0.4 \%$ of the adult population!,2 Its prevalence is age-related and increases significantly to $1-4 \%$ after 60 years of age ${ }^{1-3}$ Owing to the age structure of Turkey's population and the increasing morbidity and comorbidity, one must assume that this arrhythmia will reach an even higher prevalence. AF is associated with a significantly higher risk of systemic embolism, congestive heart failure and death!-4

$\mathrm{AF}$ and hypertension are 2 prevalent, and often coexisting, conditions in the adult population ${ }^{5-7}$ Their incidence increases with age, and they are responsible for considerable morbidity and mortality 5,6

The purpose of the present study was to determine whether a strategy that attempts to restore and maintain sinus rhythm (SR) in AF will improve survival and exercise capacity among patients with hypertension.

\section{Methods}

Patients aged $>18$ years who had hypertension and persistent $\mathrm{AF}$ for $>48 \mathrm{~h}$ were included in the study. AF was defined as having: an absence of P-waves, course or fine fibrillatory waves, and completely irregular R-R intervals.

The diagnosis of essential hypertension was defined as having BP $>140 / 90 \mathrm{mmHg}$, or current use of antihyperten-

(Received June 27, 2007; revised manuscript received November 16, 2007; accepted December 25, 2007)

Department of Cardiology, Gazi Hospital, Izmir, *Istanbul University, Institute of Cardiology and **Department of Cardiology, Hizmet Hospital, Istanbul, Turkey

Mailing address: Ahmet Yildiz, MD, Gazi Hospital, Department of Cardiology, Izmir, Turkey. E-mail: drayildiz@yahoo.com

All rights are reserved to the Japanese Circulation Society. For permissions, please e-mail: cj@j-circ.or.jp sive drugs, according to the guidelines of the 1999 World Health Organization-International Society of Hypertension (WHO/ISH) Committee?

Patients suffering from valvular heart diseases, coronary artery disease, heart failure, thyroid disease, renal failure, sick sinus syndrome, pulmonary embolism, acute pericarditis, diabetes mellitus, chronic obstructive lung disease, hypertrophic obstructive cardiomyopathy and atrial thrombus were excluded from the study.

The patients were randomly assigned to either the rhythm control group or rate control group. The patients were kept under observation for a minumum follow-up period of 3 years, with regular weekly visits in the $1^{\text {st }}$ month and then once a month thereafter. The composite endpoints of the study were embolism, death and exercise capacity for both groups.

At baseline, resting 12-lead ECG was obtained, and transthoracic echocardiography (TTE), transesophageal echocardiograph (TEE) and exercise tests were performed. At every control visit, a 12-lead ECG was taken. At the end of the $1^{\text {st }}$ year all patients underwent exercise testing.

The TTE and TEE studies were performed with an Acuson $128 \mathrm{XP} / 5$ ultrasound system. M-mode TTE was used to measure the left atrial dimension at end-systole and the LVEF, according to the recommendations of the American Society of Echocardiography. Food consumption was stopped at least $4 \mathrm{~h}$ before the TEE was done. Patients received local pharyngeal anesthesia (1\% lidocaine spray) as the only premedication, and were given effective anticoagulation either with heparin or warfarin (INR levels 2.0-3.0 or APTT 2 times control, 60-80 s) before the TEE. Patients in whom the TEE did not detect any thrombus were cardioverted to SR. For cardioversion (CV), amiodarone (administered intravenously (iv)) was used $(300 \mathrm{mg}$ over $1 \mathrm{~h}$, then $15-20 \mathrm{mg} / \mathrm{kg}$ for the remaining $23 \mathrm{~h}$ ). If $\mathrm{CV}$ was not achieved after iv loading, electrical CV was attempted. 


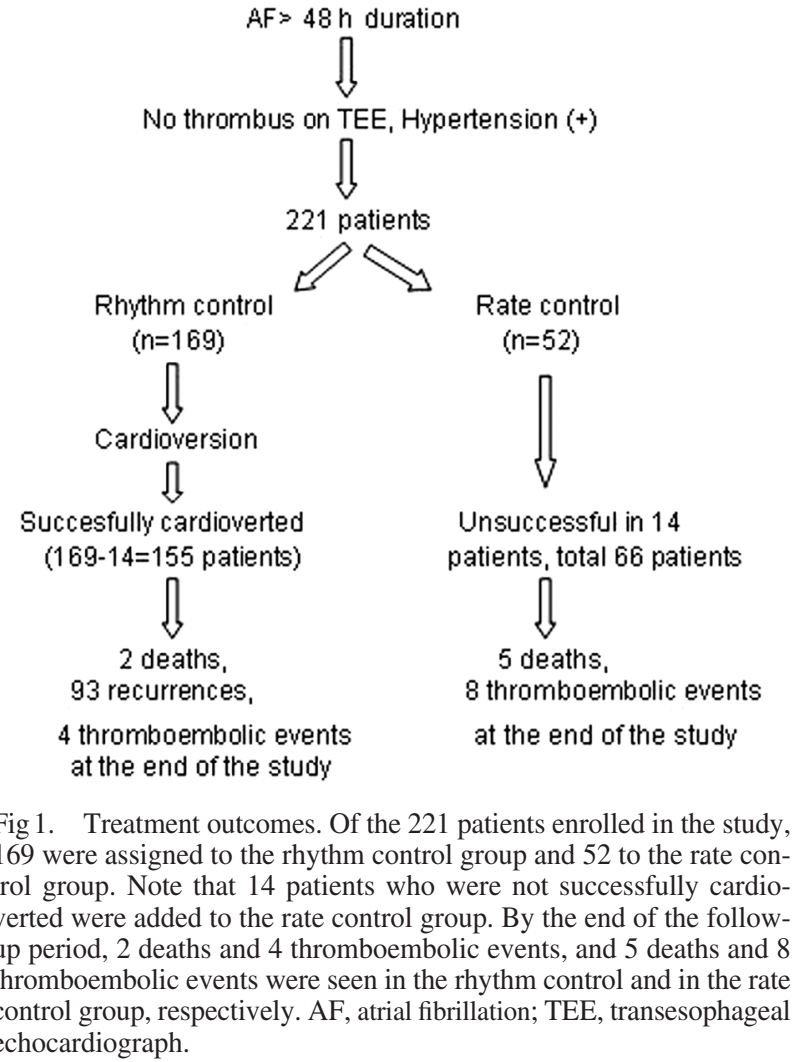

Electrical CV was started with $200 \mathrm{~J}$, repeated if necessary and then tried again with $360 \mathrm{~J}$. The procedure was brought to an end after the restoration of SR or 2 attempts at $360 \mathrm{~J}$. All patients in the rhythm control group received amiodarone ( $200 \mathrm{mg}$ q.i.d) during the follow-up period.

To detect early recurrence of arrhythmia, electrocardiographic monitoring was performed in all patients during the $1^{\text {st }} 24 \mathrm{~h}$ of their stay in hospital. SR lasting more than $24 \mathrm{~h}$ was judged to be succesful CV.

Anticoagulation (warfarin, INR ratio 2.0-3.0) was given to all patients in the rate control group during the study period but was discontinued in the rhythm control group after the $1^{\text {st }}$ month of CV.

Patients were treated with calcium antagonists, angiotensin-converting enzyme inhibitors (ACEI) and $\beta$-blockers, as needed. Patients intolerant to ACEIs were given angiotensin-II receptor antagonists (eg, losartan). For rate control, digoxin, verapamil and metoprolol were used. The target heart rate was $<80$ beats/min at rest.

Exercise capacity was determined during symptomlimited exercise tests. All patients underwent treadmill exercise testing twice, which was adjusted according to the modified Bruce protocol, $1^{\text {st }}$ before $\mathrm{CV}$ and second at the end of the $1^{\text {st }}$ year of the study. Fatigue and dyspnea were the 2 major symptoms that necessitated exercise testing to be discontinued.

\section{Statistical Analysis}

Differences between the 2 groups were detected using ANOVA, chi-square test and Student's t-test. KaplanMeier analysis was performed to estimate the cumulative rates of survival and embolic events. In all cases, a p-value of $\leq 0.05$ was considered statistically significant.
Table 1 Baseline Charecteristics of the 2 Groups

\begin{tabular}{|c|c|c|c|}
\hline & $\begin{array}{l}\text { Rhythm } \\
\text { control }\end{array}$ & $\begin{array}{c}\text { Rate } \\
\text { control }\end{array}$ & $p$ value \\
\hline No. patients & 155 & 66 & \\
\hline Age (years) & $61 \pm 9$ & $57 \pm 11$ & $N S$ \\
\hline Female (\%) & $80(51.7 \%)$ & $33(50 \%)$ & $N S$ \\
\hline Male (\%) & $75(48.3 \%)$ & $33(50 \%)$ & $N S$ \\
\hline Duration of AF (months) & $11 \pm 7$ & $13 \pm 6$ & $N S$ \\
\hline $\operatorname{LVEF}(\%)$ & $60 \pm 11$ & $63 \pm 9$ & $N S$ \\
\hline LA dimension $(\mathrm{cm})$ & $4.4 \pm 1.5$ & $4.9 \pm 1.1$ & $N S$ \\
\hline $\operatorname{LVEDD}(\mathrm{cm})$ & $5.2 \pm 0.5$ & $4.9 \pm 1.1$ & $N S$ \\
\hline Exercise duration (min) & $7.1 \pm 2.7$ & $6.6 \pm 1.3$ & NS \\
\hline MET value & $5.3 \pm 1.4$ & $4.9 \pm 1.8$ & $N S$ \\
\hline Resting heart rate (beats/min) & $110 \pm 17$ & $111 \pm 24$ & $N S$ \\
\hline $1^{\text {st }}$ stage heart rate (beats/min) & $150 \pm 26$ & $154 \pm 22$ & $N S$ \\
\hline Peak heart rate (beats/min) & $180 \pm 21$ & $182 \pm 27$ & $N S$ \\
\hline
\end{tabular}

Values are presented as the mean $\pm S D$.

NS, not significant; AF, atrial fibrillation; LVEF, left ventricular ejection fraction; LA, left atrium; LVEDD, left ventricular end-diastolic dimension; MET, multiples of oxygen consumption at rest.

Table 2 Clinical Outcomes Between 2 Groups at the End of the Study

\begin{tabular}{llll}
\hline \hline & $\begin{array}{c}\text { Rhythm } \\
\text { control }\end{array}$ & $\begin{array}{c}\text { Rate } \\
\text { control }\end{array}$ & p value \\
\hline All embolic events (\%) & $4(6 \%)$ & $8(12 \%)$ & $N S$ \\
Cerebral embolism (\%) & $2(3 \%)$ & $2(3 \%)$ & $N S$ \\
TIA (\%) & $2(3 \%)$ & $4(6 \%)$ & $N S$ \\
Peripherial embolism (\%) & 0 & $2(3 \%)$ & $N S$ \\
Death from all causes (\%) & $2(3 \%)$ & $5(7 \%)$ & $N S$ \\
Embolic death (\%) & $1(1 \%)$ & $2(3 \%)$ & $N S$ \\
Pump failure death (\%) & 0 & $1(1 \%)$ & $N S$ \\
Sudden death (\%) & $1(1 \%)$ & $2(3 \%)$ & NS \\
\hline
\end{tabular}

TIA, transient ischemic attack. Other abbreviation see in Table 1.

\section{Results}

A total of 221 patients, without thrombus in the left atrium, as determined by TEE, were randomly assigned to either the rhythm control $(n=155)$ or rate control $(n=66)$ groups. Fourteen patients who could not be cardioverted were added to the rate control group (resulting in 155 patients in the rhythm control group and 66 patients in the rate control group; Fig 1).

The avarege age of the patients was $61 \pm 9$ and $57 \pm 11$ years in the rhythm and rate control groups, respectively $(\mathrm{p}=\mathrm{NS})$. The average follow-up period was $39 \pm 21$ and $40 \pm$ 19 months in the rhythm and rate control groups, respectively $(\mathrm{p}=\mathrm{NS})$.

Baseline characteristics with regard to the duration of $\mathrm{AF}$, and echocardiographic and exercise parameters were similar in both groups (Table 1). There were no differences between exercise duration, resting, first-stage and peak heart rates between the 2 groups at baseline.

Of 169 patients with AF, 155 (91.7\%) were successfully cardioverted to SR. Fourteen patients who could not be cardioverted were then included in the rate control group. No thromboembolic events occurred in hospital.

One hundred and twenty-one patients (54.7\%) completed the 3-year follow-up study. In the rhythm control group, 62 patients (40\%) were in SR at the end of the follow-up period. All of the patients were in AF in the rate control group at the end of the 3-year follow-up period.

The embolic event rates and the overall mortality of the patients in both groups were similar at the end of the study 



Fig 2. Cumulative probability of survival is shown.
Table 3 Comparing Exercise Test Parameters in the Rhythm Control Group at the End of the $1^{\text {st }}$ Year

\begin{tabular}{lccr}
\hline \hline & Baseline & At 1 year & p value \\
\hline Exercise duration (min) & $7.1 \pm 2.7$ & $9.1 \pm 2.7$ & $<0.0001$ \\
MET value & $5.3 \pm 1.4$ & $6.3 \pm 1.4$ & 0.0005 \\
Resting heart rate (beats/min) & $110 \pm 17$ & $84 \pm 8$ & 0.0007 \\
$1^{\text {st }}$ stage heart rate (beats/min) & $150 \pm 26$ & $104 \pm 11$ & $<0.0001$ \\
Peak heart rate (beats $/$ min) & $180 \pm 21$ & $146 \pm 21$ & $<0.0001$
\end{tabular}

Values are presented as the mean $\pm S D$.

Abbreviations see in Table 1.

(Table 2; Figs 2,3). There were 2 deaths $(3.22 \%)$ in the rhythm control group and 5 deaths $(7.57 \%)$ in the rate control group ( $\mathrm{p}=\mathrm{NS})$. There were 4 embolic events $(6.45 \%)$ in the rhythm control group and 8 embolic events $(12.12 \%)$ in the rate control group ( $\mathrm{p}=\mathrm{NS}$ ) (Figs 2,3). At the time of the embolic events, 3 patients from the rhythm control group were in $\mathrm{AF}$ and 1 patient was in SR.

There were significant differences between the 2 treatment strategies with respect to exercise capacity, as measured by exercise duration, at the end of the $1^{\text {st }}$ year $(\mathrm{p}<$ 0.0001; Tables 3,4). Although the duration of exercise had increased in both treatment groups, it was statistically significant only in the rhythm control group $(\mathrm{p}<0.0001$; Tables 3,4).

No major bleeding occurred in either of the groups. By the end of the follow-up period, 4 minor $(6.06 \%)$ bleeding cases and $1(1.61 \%)$ minor bleeding case was observed in
Table 4 Comparing Exercise Test Parameters in the Rate Control Group at the End of the $1^{\text {st }}$ Year

\begin{tabular}{lccc}
\hline \hline & Baseline & At 1 year & p value \\
\hline Exercise duration (min) & $6.6 \pm 1.3$ & $7.1 \pm 2.1$ & NS \\
MET value & $4.9 \pm 1.8$ & $5.5 \pm 2.0$ & NS \\
Resting heart rate (beats $/$ min) & $111 \pm 24$ & $89 \pm 15$ & $<0.0001$ \\
$1^{\text {st }}$ stage heart rate (beats/min) & $154 \pm 22$ & $138 \pm 18$ & $<0.0001$ \\
Peak heart rate (beats $/ \mathrm{min}$ ) & $182 \pm 27$ & $168 \pm 28$ & 0.0041 \\
\hline
\end{tabular}

Values are presented as the mean $\pm S D$.

Abbreviations see in Table 1.

the rate control group and the rhythm control group, respectively.

\section{Discussion}

$\mathrm{AF}$ is the most common sustained arrhythmia encountered in clinical practice!,3 The incidence of AF rises progressively with age from $0.5 \%$ for the $50-59$-year age group to almost $9 \%$ for the $80-89$-year age group? AF is also is a major cause of stroke in the elderly, ${ }^{10}$ and is responsible for $7-31 \%$ of all ischemic strokes ${ }^{11}$ Studies have shown that $50-70 \%$ of patients with stroke associated with $\mathrm{AF}$, died or had a severe permanent neurologic deficit!2,13 Also, it is associated with increased risk of mortality and cardiovascular events ${ }^{14}$

Hypertension is a major cause of non-rheumatic $\mathrm{AF}^{15} \mathrm{In}$ patients with hypertension, the risk of AF increases with age 
and left ventricular mass 5 The prognostic value of hypertension in $\mathrm{AF}$ is somewhat conflicting.

Advantages of restoring SR in cases with AF include a marked relief of symptoms, improved cardiac hemodynamics and a decrease in the number of thromboembolic events? 3,10

The results of the Atrial Fibrillation Follow-up Investigation of Rhythm Management (AFFIRM) and Rate Control Versus Electrical Cardioversion (RACE) studies showed that the risk of embolism and the relief of symptoms does not decrease after restoring SR 16-21 $^{-1}$

In the AFFIRM study, patients who had at least 1 other risk factor for stroke and death were randomly assigned to either the rate or rhythm control group ${ }^{16-21}$ In that trial, risk factors were: being aged $\geq 65$ years, having systemic hypertension, diabetes mellitus, congestive heart failure, transient ischemic attack, prior stroke, left atrium $\geq 50 \mathrm{~mm}$, and left ventricular fractional shortening of $<25 \%$ or left ventricular ejection fraction of $<0.40$. Hypertension was present in $71 \%$ of participants in the AFFIRM trial. Patients were followed up for approximately 5 years and no difference was found in terms of stroke and mortality between the 2 groups. Most of the strokes occurred in patients whose warfarin therapy was stopped or with an INR of $<2.0$. Thus, anticoagulation was recommended to all patients with risk factors for stroke. It was concluded that the primary treatment in AF should be the rate control.

In the RACE trial, 512 patients with AF of $>24 \mathrm{~h}$ but $<1$ year duration were randomly assigned to either the rate control or rhythm control group, and followed for 3 years ${ }^{19-20}$ At the end of the study, it was shown that rhythm control was not superior to rate control, and that rate control should be the preferred treatment for those patients with high risks for recurrence or potential risks with antiarrhythmic treatment and, especially, for patients with hypertension.

The previous 2 studies showed that the $\mathrm{CV}$ of patients with high risk for stroke provided no benefit over rate control, so rate control was established as the primary therapy for this group of patients.

Also, in the Strategies of Treatment in Atrial Fibrillation (STAF) trial no difference was found in terms of morbidity and mortality among patients with AF who were randomly assigned to the rate or rhythm control group.2

For patients with AF, it is important to recognize that improved exercise tolerance is just as important as improved survival. So, one of the goals of therapy for AF should be to improve patients' exercise tolerance. The Pharmacological Intervention in Atrial Fibrillation (PIAF) trial showed that rhythm control leads to better exercise tolerance compared with rate control, 23 which is in agreement with the result of the present study. Symptomatic AF is one of the indications to restore SR.

In conclusion, although patients with $\mathrm{AF}$ and hypertension recieve considerable benefits from the restoration of SR in terms of exercise capacity, no significant difference was found in terms of the mortality and embolic event rates. Thus, rate control is an acceptable primary strategy for asymptomatic patients with $\mathrm{AF}$ and hypertension.

\section{References}

1. Pai SM, Pai RG. Management of atrial fibrillation. $N$ Engl J Med 1992; 327: 1031; 1031 - 1032 (Discussion).

2. Hennersdorf MG, Strauer BE. Atrial fibrillation. Internist (Berl) 2006; 47: $990-1000$.
3. Fuster V, Ryden LE, Asinger RW, Cannom DS, Crijns HJ, Frye RL, et al. ACC/AHA/ESC guidelines for the management of patients with atrial fibrillation: Executive summary: A Report of the American College of Cardiology/American Heart Association Task Force on Practice Guidelines and the European Society of Cardiology Committee for Practice Guidelines and Policy Conferences (Committee to Develop Guidelines for the Management of Patients With Atrial Fibrillation): Developed in Collaboration With the North American Society of Pacing and Electrophysiology. J Am Coll Cardiol 2001; 38: $1231-1266$.

4. Falk RH. Atrial fibrillation. N Engl J Med 2001; 334: 1067-1077.

5. Verdecchia P, Reboldi G, Gattobigio R, Bentivoglio M, Borgioni C, Angeli F, et al. Atrial fibrillation in hypertension: Predictors and outcome. Hypertension 2003; 41: 218-223.

6. Healey JS, Connolly SJ. Atrial fibrillation: Hypertension as a causative agent, risk factor for complications, and potential therapeutic target. Am J Cardiol 2003; 91: 9-14.

7. Ciaroni S, Cuenoud L, Bloch A. Clinical study to investigate the predictive parameters for the onset of atrial fibrillation in patients with essential hypertension. Am Heart J 2000; 139: 814-819.

8. Chalmers J, MacMahon S, Mancia G, Whitworth J, Beilin L, Hansson L, et al. 1999 World Health Organization-International Society of Hypertension Guidelines for the management of hypertension: Guidelines sub-committee of the World Health Organization. Clin Exp Hypertens 1999; 21: 1009-1060.

9. Wolf PA, Abbott RD, Kannel WB. Atrial fibrillation as an independent risk factor for stroke: The Framingham Study. Stroke 1991; 22: 983-988.

10. Prystowsky EN, Benson DW Jr, Fuster V, Hart RG, Kay GN, Myerburg RJ, et al. Management of patients with atrial fibrillation: A Statement for Healthcare Professionals: From the Subcommittee on Electrocardiography and Electrophysiology, American Heart Association. Circulation 1996; 93: $1262-1277$.

11. Kannel WB, Abbott RD, Savage DD, McNamara PM. Epidemiologic features of chronic atrial fibrillation: The Framingham study. $N$ Engl J Med 1982; 306: 1018-1022.

12. Morley J, Marinchak R, Rials SJ, Kowey P. Atrial fibrillation, anticoagulation, and stroke. Am J Cardiol 1996; 77: 38A-44A.

13. Cairns JA, Connolly SJ. Nonrheumatic atrial fibrillation: Risk of stroke and role of antithrombotic therapy. Circulation 1991; 84: $469-481$.

14. Okin PM, Wachtell K, Devereux RB, Harris KE, Jern S, Kjeldsen $\mathrm{SE}$, et al. Regression of electrocardiographic left ventricular hypertrophy and decreased incidence of new-onset atrial fibrillation in patients with hypertension. JAMA 2006; 296: 1242-1248.

15. Hennersdorf MG, Strauer BE. Arterial hypertension and cardiac arrhythmias. J Hypertens 2001; 19: 167-177.

16. AFFIRM Investigators; Atrial Fibrillation Follow-up Investigation of Rhythm Management. Baseline characteristics of patients with atrial fibrillation: The AFFIRM Study. Am Heart J 2002; 143: 991 - 1001 .

17. Epstein AE, Vidaillet H, Greene HL, Curtis AB, Ellenbogen KA, Simmons T, et al. Frequency of symptomatic atrial fibrillation in patients enrolled in the Atrial Fibrillation Follow-up Investigation of Rhythm Management (AFFIRM) study. J Cardiovasc Electrophysiol 2002; 13: 667-671.

18. Wyse DG, Waldo AL, DiMarco JP, Domanski MJ, Rosenberg Y, Schron EB, et al; Atrial Fibrillation Follow-up Investigation of Rhythm Management (AFFIRM) Investigators. A comparison of rate control and rhythm control in patients with atrial fibrillation. $N$ Engl J Med 2002; 347: 1825-1833.

19. Coletta A, Thackray S, Nikitin N, Cleland JG. Clinical trials update: Highlights of the scientific sessions of The American College of Cardiology 2002: LIFE, DANAMI 2, MADIT-2, MIRACLE-ICD, OVERTURE, OCTAVE, ENABLE 1 \& 2 , CHRISTMAS, AFFIRM, RACE, WIZARD, AZACS, REMATCH, BNP trial and HARDBALL. Eur J Heart Fail 2002; 3: 381-388.

20. Saxonhouse SJ, Curtis AB. Risks and benefits of rate control versus maintenance of sinus rhythm. Am J Cardiol 2003; 91: 27D-32D.

21. Khairy P, Nattel S. New insights into the mechanisms and management of atrial fibrillation. CMAJ 2002; 167: 1012-1020.

22. Louis A, Cleland JG, Crabbe S, Ford S, Thackray S, Houghton T, et al. Clinical Trials Update: CAPRICORN, COPERNICUS, MIRACLE, STAF, RITZ-2, RECOVER and RENAISSANCE and cachexia and cholesterol in heart failure: Highlights of the Scientific Sessions of the American College of Cardiology, 2001. Eur J Heart Fail 2001; 3: $381-387$.

23. Hohnloser SH, Kuck KH, Lilienthal J. Rhythm or rate control in atrial fibrillation-Pharmacological Intervention in Atrial Fibrillation (PIAF): A randomised trial. Lancet 2000; 356: 1789-1794. 